Volume 10, Nomor 2, November 2018, pp 160-169 Copyright (C) 2017 Jurnal Akuntansi Maranatha, Program Studi Akuntansi, Fakultas Ekonomi, Universitas Kristen Maranatha. ISSN 2085-8698 | e-ISSN 2598-4977. http://journal.maranatha.edu

\title{
Audit Operasional: Solusi Atas Biaya Dead Stock
}

\author{
Christian Linardo \\ Price Waterhouse Cooper (PWC) \\ christ.linardo@id.pwc.com \\ Carmel Meiden \\ Fakultas Ekonomi Institut Bisnis dan Informatika Kwik Kian Gie \\ carmel.meiden@kwikkiangie.ac.id \\ Eddy Winarso \\ Fakultas Ekonomi Universitas Widyatama \\ eddy.winarso@widyatama.ac.id
}

\begin{abstract}
In manufacturing company, effectiveness and efficiency of inventory control can affect the corporate earnings significantly. According to the observation, the author found a large number of dead stock at PT X. Therefore, the author decided to carry out an operational audit of inventory control in the company.The audit steps are preliminary audit, test of management control, audit in depth, reporting, and follow up. The methods used by the author to collect the data are observation for six months, focus group discussion with management, internal control questionnaires for three middle managers, and data documentation. According to the analysis' result, author found large number of dead stock. The accumulation of dead stock disturbed corporate cash flow so that the company had to make loans to third parties and company had to pay interest charges. In addition, there's also the exhibition cost. The accumulated expense of dead stock for 2017 was recorded at IDR 522,130,391.43. Several of main causes of the dead stock are the lack of market research, lach of control by stock keeper, and other factors. The author suggested internal improvement such as the determination of clear boundaries for inventories, and external improvement such as doing market research more often.
\end{abstract}

Keywords: Operational Audit, Inventory, Effectiveness and Efficiency 


\section{Pendahuluan}

Masalah yang seringkali timbul pada setiap perusahaan salah satunya adalah masalah mengenai pengendalian persediaan barang. Di mana persediaan yang sedikit dapat menyebabkan perusahaan kekurangan stock sehingga tidak mampu mencukupi permintaan pasar namun kuantitas barang yang berlebihan juga dapat menyebabkan tingginya beban persediaan sehingga keuntungan perusahaan menjadi tidak optimal.

Namun karena rasa optimis yang cukup tinggi maka beberapa perusahaan memutuskan untuk memproduksi barang lebih banyak dari kebutuhan guna menghindari masalah stock out. Hingga pada akhirnya timbul masalah baru yakni adanya penumpukan barang karena analisa yang kurang akurat dari pihak-pihak yang terkait saat memesan barang. Oleh karena itu peran seorang auditor operasional dalam kasus ini sangatlah penting guna mencari penyebab timbulnya masalah.

Dalam hal ini PT $X$ sebagai perusahaan yang bergerak di bidang bisnis perhiasan emas dan berlian memiliki masalah mengenai penumpukan barang jadi. Dipandang dari sudut pandang umur barang, barang jadi tersebut memang tidak akan kadaluarsa seperti barang-barang konsumsi. Namun lamanya perputaran barang jadi menyebabkan terganggunya arus kas perusahaan. Di mana arus kas yang tersendat memaksa perusahaan untuk melakukan pinjaman ke pihak lain sehingga timbul biaya bunga yang nilainya cukup besar.

Dari pengamatan awal yang dilakukan, didapatkan kiranya hingga bulan Juni tahun 2017 PT X menderita kerugian akibat dead stock sebanyak IDR 214.894.616,35. Berikut diagram akumulasi biaya dead stock yang dapat digambarkan:

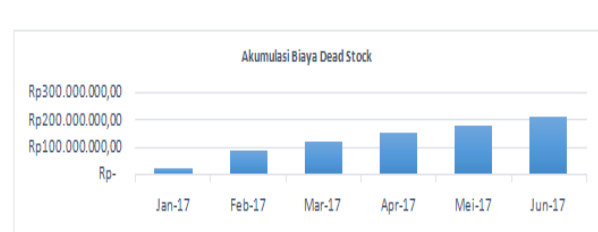

\section{Gambar 1}

Cuplikan diskusi peneliti dengan manajer bagian persediaan, ditambah berbagai informasi seperti: dead stock, nilai persediaan barang dagangan perhiasan, biaya pameran, biaya bunga, penjualan, menjadikan hadirnya konsep biaya dead stock sebagai konsep risiko. Konsep risiko muncul ketika manajer stock keeper mengungkapkan biaya dead stock, lalu kemudian laporan dead stock sebagai fakta yang terdapat dalam perusahaan. Dead stock pada dasarnya konsep investasi dalam fisik kuantitas dan nilai USD persediaan yang belum terjual selama waktu tertentu. Semakin lama periode tidak terjualnya persediaan maka risiko dead stock semakin tinggi. Kemudian nilai persediaan akhir sama seperti dead stock, hanya dalam satuan nilai rupiah. Biaya pameran pada dasarnya merupakan beban yang dikeluarkan untuk menjual persediaan dead stock, biaya bunganya merupakan beban yang harus dipikul karena bunga harus dibayarkan, yang timbul dari pembelian bahan emas dan perhiasan berlian hingga siap dijual, namun karena belum terjual maka risiko bunga menjadi dipikul oleh perusahaan. Penjualan merupakan dasar perhitungan yang digunakan untuk pengali proporsi bagi munculnya angka pembatas toleransi dead stock di mana perusahaan memberikan ketetapan yaitu sebesar 3\% dari penjualan bersih untuk barang di mana perusahaan memberikan ketetapan yaitu sebesar 3\% dari penjualan bersih untuk barang yang berumur lebih dari enam bulan. Setelah didapat angka toleransi nilai dead stock maka dikalikan dengan $10 \%$ yang merupakan suku bunga rata-rata atas pinjaman perusahaan pada pihak ke tiga. 


\section{Kerangka Teoritis dan Hipotesis}

\section{Audit Operasional}

Messier et al (2014:38) berpendapat bahwa audit operasional merupakan examination secara sistematis terhadap sebagian atau semua kegiatan organisasi untuk mengevaluasi apakah sumber-sumber daya telah digunakan secara efektif dan efisien. Audit operasional sendiri bertujuan untuk menilai kinerja, mengidentifikasi wilayahwilayah untuk perbaikan, dan mengembangkan rekomendasi. Sementara tujuan audit operasional menurut Agoes (2008:173) ada empat yaitu:

1. Untuk menilai kinerja (performance) dari manajemen dan berbagai fungsi dalam perusahaan.

2. Untuk menilai apakah persediaan perusahaan telah digunakan secara efisien dan ekonomis.

3. Untuk menilai efektivitas perusahaan dalam mencapai tujuan yang telah ditetapkan oleh manajemen puncak.

4. Untuk memberikan rekomendasirekomendasi kepada manajemen puncak untuk memperbaiki kelemahankelemahan yang terdapat dalam penerapan system pengendalian internal dan prosedur operasional perusahaan dalam rangka meningkatkan efisiensi, ke ekonomisan dan keefektivan dari kegiatan operasional perusahaan.

Maka dapat disimpulkan secara ringkas bahwa audit operasional dilakukan untuk mengevaluasi tingkat efisiensi dan efektivitas pelaksanaan aktivitas suatu organisasi. Audit operasional mengidentifikasi timbulnya penyelewengan dan penyimpangan yang terjadi dan kemudian membuat laporan yang berisi rekomendasi tindakan perbaikan selanjutnya. Audit operasional merupakan salah satu alat pengendalian yang membantu dalam mengelola perusahaan dengan penggunaan sumber daya yang ada dalam pencapaian tujuan perusahaan dengan efektif dan efisien.

Menurut Arens et al (2014:839), terdapat tiga tahapan yang dilakukan dalam melakukan audit operasional yaitu sebagai berikut:

1. Perencanaan

Perencanaan dalam audit operasional serupa dengan perencanaan untuk audit atas laporan keuangan historis. Seperti dalam audit laporan keuangan, auditor operasional harus menentukan lingkup penugasan dan menyampaikan hal itu kepada unit organisasional, juga perlu menentukan staff yang tepat dalam penugasan, mendapatkan informasi mengenai latar belakang unit organisasional memakai struktur pengendalian internal, serta menentukan bahan bukti yang tepat yang harus dikumpulkan. Perbedaan utama antara perencanaan audit operasional dengan audit laporan keuangan adalah sangat banyaknya keragaman dalam audit operasional. Oleh karena keragamannya, seringkali sulit menentukan tujuan khusus pada suatu audit operasional, sehingga tujuannya akan didasarkan pada kriteria yang dikembangkan untuk penugasan.

2. Pengumpulan dan Evaluasi Bahan Bukti

Dengan cara yang sama seperti pada audit keuangan, auditor operasional harus mengumpulkan cukup bahan bukti yang kompeten agar dapat menjadi dasar yang layak guna menarik suatu kesimpulan mengenai tujuan yang sedang diuji.

3. Pelaporan danTindak Lanjut

Dua perbedaan utama dalam laporan audit operasional dan keuangan yang mempengaruhi laporan audit operasional. Pertama, dalam audit operasional, laporan biasanya dikirim hanya untuk pihak manajemen, dan satu salinan untuk unit yang diperiksa. Tidaka danya pemakaian pihak ke tiga, mengurangi pembakuan kata-kata 
dalam laporan audit operasional. Kedua, keragaman audit operasional memerlukan penyusunan laporan secara khusus untuk menyajikan ruang lingkup audit, temuan-temuan dan rekomendasi-rekomendasi.

Hubungan kedua faktor ini mengakibatkan banyak perbedaan dalam laporan audit operasional. Penulisan laporan seringkali memakan banyak waktu agar temuantemuan dan rekomendasi disampaikan secara jelas. Tindak lanjut merupakan hal yang biasa dalam audit operasional di saat rekomendasi-rekomendasi disampaikan kepada manajemen, yang tujuannya adalah untuk memastikan apakah perubahanperubahan yang direkomendasikan telah dilakukan dan jika tidak apakah alasannya.

\section{Efisiensi dan Efektivitas}

Menurut Arens et al (2014:834) mengenai efisiensi adalah sebagai berikut:

"Like effectiveness, there must be defined criteria for what is meant by doing things more efficiently before operational auditing can be meaningful. It is often easier to set efficiency than effectiveness criteria if efficiency is defined as reducting cost without reducing effectiveness. For example, if two different production processes manufacture a product of identical quality, the process with the lower cost is considered more efficient."

Menurut Pickett (2010:315) mendefinisikan efektivitas sebagai berikut:

"Effectiveness is a bottom-line concept based on the notion that management is able to set objectives and control resources in such a way as to ensure that these goals are in fact achieved. The link between controls and objectives becomes clear, and audit must be able to understand the fundamental needs of management as it works to its goals. The complexities behind the concept of effectiveness are great, and by building this into the audit definition, the audit scope becomes potentially very wide."
Dari definisi tersebut, maka dapat disimpulkan bahwa efektivitas lebih fokus dan mengacu terhadap tingkat pencapaian pada suatu tujuan.

Maka disimpulkan oleh Arens et al (2014:834) efisiensi dan efektivitas adalah sebagai berikut:

"In general, effectiveness refers to meeting objectives, such as producing parts without defects. Efficiency refers to determining the resources used to achieve those objectives, such as determining whether parts are produced at minimum cost."

\section{Tindakan Koreksi}

Pada audit operasional, ketika ditemukan permasalahan maka tindakan yang perlu diambil oleh manajemen perusahaan adalah tindakan koreksi. Di mana dengan tindakan tersebut perusahaan dapat memperbaiki masalah yang telah timbul. Dalam bagian ini penulis akan menjelaskan mengenai teknik-teknik yang berguna untuk mendiagnosa penyebab masalah dan mengidentifikasikan solusinya. Menurut Blocher (2010:768) teknik-teknik tindakan koreksi di antaranya adalah sebagai berikut:

a. Histogram

A histogram is a graphical representation of the frequency of attributes or events in a given set of data. Patterns or variations that are often difficult to see in a set of numbers become clear in a histogram.

b. Pareto Diagram

A Pareto diagram is a histogram of factors contributing to a specified quality problem, ordered from the most to the least frequent. Joseph Juran observed in the 1950s that a few causes usually account for most of the quality problems, thus the name Pareto. 


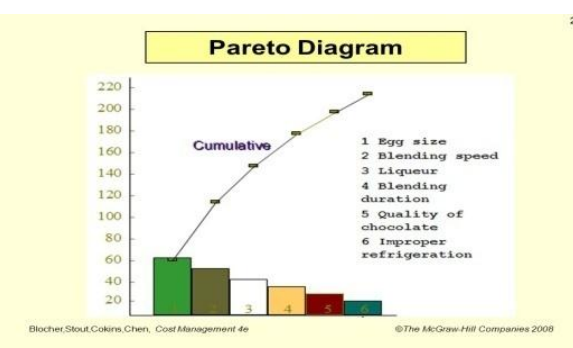

Gambar 2

Diagram Pareto

c. Cause-and-Effect Diagram

The cause-and-effect, or "fishbone," diagram organizes a chain of causes and effects to sort out root causes of an identified quality problem. Karou Ishikawa discovered that for situations with myriad factors the number of factors that influenced a process or contributed to a quality problem were often overwhelming. He developed cause-and-effect diagrams as an organizing aid.

A cause-and-effect diagram consists of a spine, ribs, and bones. At the right end of the horizontal spine is the quality problem at hand. The spine connects causes to the effect, the quality problem

Typical main causes for quality problems in manufacturing operations are

-Machines

-Materials

-Methods

-Manpower

Some users refer to the four main categories as $4 M$.

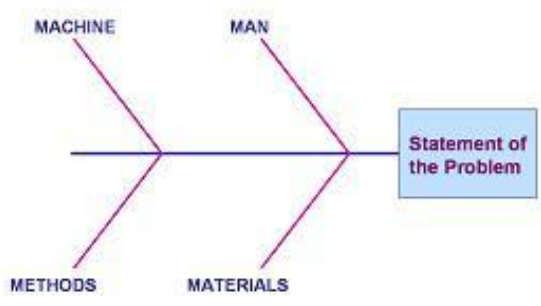

\section{Gambar 3}

Diagram Tulang Ikan

\section{Pengendalian Persediaan}

Definisi persediaan menurut Ikatan Akuntansi Indonesia (2008:2),

Persediaan adalah aset yang tersedia untuk dijual dalam kegiatan usaha biasa; dalam proses produksi untuk penjualan tersebut; atau dalam bentuk bahan atau perlengkapan untuk digunakan dalam proses produksi atau pemberian jasa.

Heizer et al (2016:441) mengatakan semua organisasi memiliki beberapa jenis system perencanaan dan system pengendalian persediaan, karena pada hakekatnya perencanaan dan pengendalian persediaan perlu diperhatikan. Dari definisi di atas penulis dapat menyimpulkan bahwa pengendalian persediaan adalah suatu usaha yang dilakukan oleh pihak perusahaan dalam rangka memenuhi kebutuhan perusahaan baik dalam proses produksi maupun proses jual-beli secara optimal.

\section{Metode Penelitian}

Teknik pengumpulan data yang digunakan adalah sebagai berikut: 


\section{Observasi / Pengamatan}

Penulis mendatangi dan mengamati langsung ke perusahaan untuk memperoleh gambaran yang lebih jelas mengenai situasi perusahaan. Dari hasil observasi yang dimulai pada bulan Juli 2017, penulis melihat barang dagang secara fisik yang berumur lebih dari enam bulan.

\section{Wawancara}

Penulis mendatangi perusahaan untuk melakukan wawancara dengan entitasentitas terkait dengan isu mengenai pengendalian persediaan. Wawancara dimulai dari manajer stock keeper Bapak AL dan top management.

\section{Kuisioner}

Teknik pengumpulan data yang dilakukan dengan cara memberikan pertanyaan tertulis kepada karyawan pada bagian stock keeper, finance and accounting, dan purchasing and pricing untuk dijawab agar diperoleh data yang berhubungan dengan masalah penelitian. Kegiatan tersebut bertujuan untuk memperkuat hasil dari pengamatan dan wawancara yang telah dilakukan oleh penulis.

\section{Dokumentasi}

Penulis juga mempelajari dokumendokumen perusahaan yang berhubungan dengan objek penelitian.

\section{Hasil Penelitian dan Pembahasan}

Tahapan audit yang diterapkan adalah sebagai berikut:

\section{Audit Pendahuluan}

Penulis meninjau perusahaan, mengumpulkan dokumen-dokumen tertulis yang berhubungan dengan pengelolaan persediaan barang, serta wawancara dengan manajemen untuk mendapatkan gambaran yang nyata mengenai operasi perusahaan serta indikasi permasalahan-permasalahan yang ada.

Dari audit pendahuluan yang dilakukan, penulis dapat menyusun memoranda survei seperti yang ditampilkan pada tabel 1.

\section{Review dan Pengujian Manajemen}

Hal-hal yang dilakukan untuk mereview dan melakukan pengujian pengendalian manajemen adalah dengan pengisian Internal Control Questionnaries oleh 3 bagian perusahaan yaitu Stock Keeper, Purchasing, dan Finance \& Accounting.

\section{Tabel 1}

Memoranda Survei

\begin{tabular}{|c|c|c|c|c|}
\hline No & Falkta & Kriteria & Dampda & Sumber \\
\hline 1 & $\begin{array}{lr}\text { Ditemukan } & \text { banyalk } \\
\text { persediaan } & \text { barang } \\
\text { jadi } & \text { yang } \\
\text { menumpulk } & \text { dan } \\
\text { berumur di atas } 6 \\
\text { bulan (barang yang } \\
\text { berumur di atas } 6 \\
\text { bulan dianggap } \\
\text { sebagai dead stock }\end{array}$ & $\begin{array}{|lr|}\text { Tidalk } & \text { ada } \\
\text { persediaan } & \text { barang } \\
\text { jadi yang berumur } \\
\text { lebih darit } 6 \text { bulan }\end{array}$ & 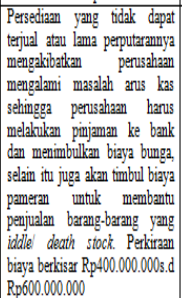 & $\begin{array}{l}\text { Hasil wawancara } \\
\text { dengan } \\
\text { manajemen dan } \\
\text { laporan keuangan } \\
\text { tahun } 2017\end{array}$ \\
\hline 2 & $\begin{array}{l}\text { Ditemukan } \\
\text { tingginya tingkat } \\
\text { perputaran tenaga } \\
\text { kerja }\end{array}$ & $\begin{array}{l}\text { Tingkat perputaran } \\
\text { tenaga keja di } \\
\text { bawah } 5 \% \text { sebagai } \\
\text { penetapan dari } \\
\text { perusahaan (10 } \\
\text { orang dalam satu } \\
\text { tahun) }\end{array}$ & 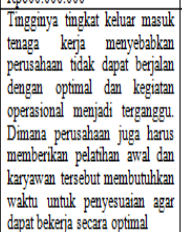 & $\begin{array}{l}\text { Hasilwawancara } \\
\text { dengan } \\
\text { manajemen }\end{array}$ \\
\hline 3 & $\begin{array}{l}\text { Ditemulkan } \\
\text { banyaluya } \\
\text { kebjiakan yang } \\
\text { dikeluarkan } \\
\text { manajemen }\end{array}$ & $\begin{array}{l}\text { Sistem Operasi } \\
\text { Prosedur bersifat } \\
\text { balku }\end{array}$ & $\begin{array}{l}\text { Banyaluyya kebijakan yang } \\
\text { dikeluarkan oleh manajemen } \\
\text { menyebabkan Sistem Operasi } \\
\text { Prosedur sering dirdakan } \\
\text { perubahan. }\end{array}$ & $\begin{array}{l}\text { Hasi wawancara } \\
\text { dengan } \\
\text { manajemen }\end{array}$ \\
\hline
\end{tabular}

Tabel 2

Tabel Jawaban Kuisioner

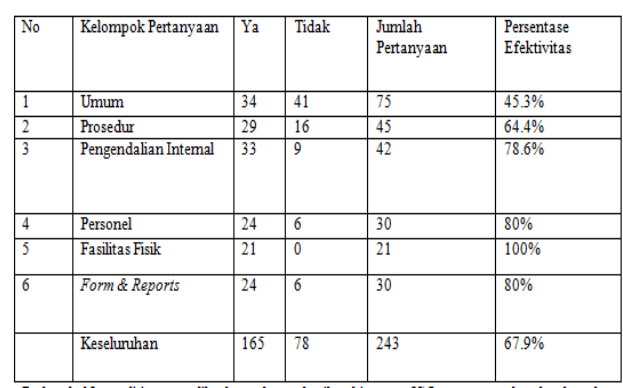

Pada tabel 2 peneliti memperlihatkan rekapan hasil perhitungan $I C Q$ yang secara 
keseluruhan dapat dilihat bahwa besarnya efektivitas keseluruhan adalah sebesar $67.9 \%$ yang mana berada dalam kriteria belum efektif. Selain itu, pada bagian ini peneliti memperlihatkan jumlah kerugian yang diderita oleh perusahaan setiap bulannya dengan mengurutkan biaya yang terbesar ke bulan yang terendah sehingga terbentuk diagram pareto seperti pada gambar 4.1 yang berdasarkan data pada tabel 3 berikut:

Tabel 3

Akumulasi Beban Dead Stock

\begin{tabular}{|l|l|l|l|}
\hline DATE & DS EXPENSE(IDR) & ACCUMULATED (IDR) & Batasan Beban DS (IDR) \\
\hline Jan-17 & $22,583,464.57$ & $22,583,464.57$ & $227,683,100.24$ \\
\hline Feb-17 & $66,579,255.52$ & $89,162,720.09$ & $227,683,100.24$ \\
\hline Mar-17 & $30,272,205.69$ & $119,434,925.78$ & $227,683,100.24$ \\
\hline Apr-17 & $31,032,377.35$ & $150,467,303.13$ & $227,683,100.24$ \\
\hline May-17 & $30,529,096.80$ & $180,996,399.93$ & $227,683,100.24$ \\
\hline Jun-17 & $33,898,216.41$ & $214,894,616.35$ & $227,683,100.24$ \\
\hline Jul-17 & $34,892,061.24$ & $249,786,677.59$ & $227,683,100.24$ \\
\hline Aug-17 & $37,833,914.77$ & $287,620,592.36$ & $227,683,100.24$ \\
\hline Sep-17 & $32,461,772.64$ & $320,082,365.00$ & $227,683,100.24$ \\
\hline Oct-17 & $120,151,663.11$ & $440,234,028.11$ & $227,683,100.24$ \\
\hline Nov-17 & $38,974,813.06$ & $479,208,841.17$ & $227,683,100.24$ \\
\hline Dec-17 & $42,921,550.25$ & $522,130,391.43$ & $227,683,100.24$ \\
\hline
\end{tabular}

Dari tabel 3 dapat terlihat bahwa akumulasi beban dead stock cukup tinggi sehingga perlu dicari tahu faktor penyebabnya. Untuk itu penulis melakukan focus group discussion dengan manajemen perusahaan dan berhasil membentuk fish bone diagram. Dari kesepuluh penyebab yang muncul pada diagram tulang ikan penulis menyusun diagram pareto berdasarkan frekuensi terjadinya. Diagram pareto dapat dilihat pada tabel 4.4 dan ditemukan 2 penyebab dengan frekuensi tertinggi yakni kurangnya informasi mengenai market wants dan kemampuan salesman yang masih kurang.

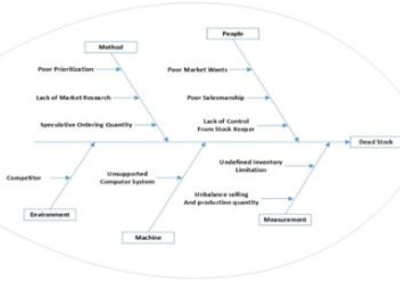

\section{Gambar 4}

Diagram Tulang Ikan Penyebab Ketidakefisienan Pengolahan Persediaan Barang Jadi

mengenai market wants menjadi pengaruh terbesar dengan frekuensi sebanyak 41 barang. Kemudian urutan kedua diikuti oleh kurangnya kemampuan salesman yang memiliki frekuensi sebanyak 37 barang.

Faktor berikutnya adalah jumlah produksi dan penjualan yang cenderung tidak seimbang di mana jumlah penjualan lebih sedikit daripada jumlah produksi. Hal tersebut menyebabkan penumpukan sebanyak 30 unit. Urutan ke empat disebabkan oleh pembatasan jumlah persediaan yang masih belum jelas dengan frekuensi sebanyak 22 barang.

Faktor lain penyebabnya penumpukan barang adalah riset pasar yang tidak dilakukan dengan baik dan rutin. Hal ini menyebabkan penumpukan barang jadi berjumlah 15 unit. Akar penyebab berikutnya adalah kuantitas pemesanan yang sifatnya spekulatif, dari pemesanan yang spekulatif tersebut menyebabkan penumpukan sebanyak 13 unit. Kontrol dari bagian persediaan yang kurang baik juga ikut mengambil bagian dari menumpuknya persediaan pada perusahaan sebanyak 10 buah.

Tiga faktor penyebab yang terakhir ialah karena kurangnya prioritas dengan frekuensi 8 unit. Diikuti dengan keberadaan pesaing yang mampu menciptakan produk serupa dengan harga jual yang lebih murah, menyumbangkan frekuensi sebanyak 5 unit. Dan yang terakhir adalah sistem komputer 
yang masih belum sempurna menyebabkan penumpukan sebanyak 3 unit.

Dari kesepuluh faktor tersebut dapat ditarik kesimpulan bahwa kurangnya informasi mengenai market wants memiliki peranan terbesar akan terjadinya penumpukan barang di PT X. Maka penulis akan merekomendasikan perusahaan untuk memulai perbaikan dari titik tersebut. Salah satu cara yang dapat direkomendasikan adalah dengan melakukan personal approach kepada pemilik toko guna mendapatkan informasi mengenai market wants yang lebih akurat.

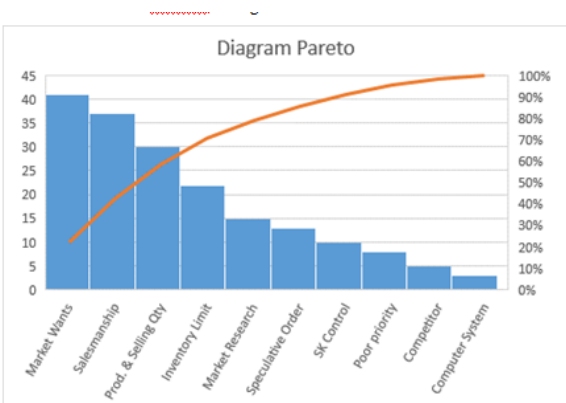

Gambar 5

Diagram Pareto Dead Stock

Penulis mulai melakukan penelitian ketika batasan dilalui pada bulan Juli 2017. Mulai dari Juli 2017, penulis melakukan audit pendahuluan yang mana menghasilkan tentative audit finding. Kemudian penulis melanjutkan dengan pengujian pengendalian manajemen dan observasi di perusahaan.

Setelah pengujian pengendalian manajemen, penulis melakukan audit terinci. Beberapa hal yang didapat di antaranya adalah fish bone dari hasil focus group discussion. Yang mana dari penyebab-penyebab pada diagram tersebut dapat diolah menjadi diagram pareto.

Setelah mengetahui bahwa market wants adalah penyebab dengan frekuensi tertinggi, maka penulis merekomendasikan untuk memulai perbaikan dari faktor tersebut. Rekomendasi yang diberikan dan diimplementasikan penulis kepada perusahaan adalah dengan melakukan personal approach kepada pemilik toko guna mendapatkan informasi mengenai market wants yang lebih akurat.

$$
\text { Hasil tindaklanjut atas }
$$

rekomendasi yang telah diberikan oleh penulis kepada manajemen perusahaan terlihat pada grafik di bulan Januari 2018 pada Gambar 5. Pada bulan Januari 2018 terlihat bahwa terjadi penurunan beban dead stock secara keseluruhan. Walaupun angkanya masih belum signifikan namun hal ini sudah merupakan hasil yang positif mengingat telah terjadi penurunan.

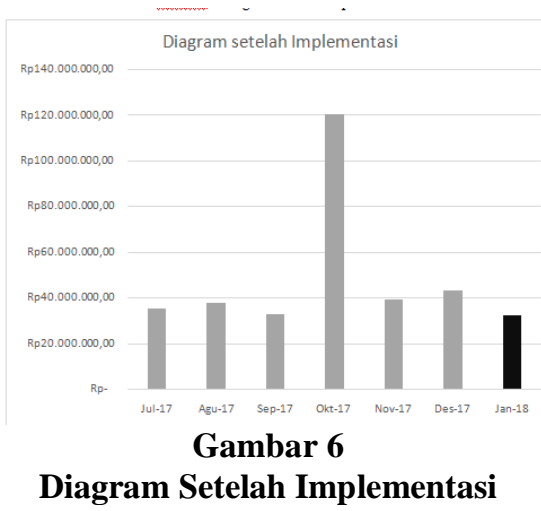

\section{Simpulan dan Saran}

\section{Simpulan}

Setelah penulis melakukan observasi, wawancara, dokumentasi, dan pembagian kuisioner pada pihak manajemen, penulis berhasil menemukan nilai dead stock barang jadi yang cukup tinggi pada PT X. Tingginya nilai dead stock mengakibatkan terganggunya arus kas perusahaan sehingga memaksa perusahaan untuk melakukan pinjaman ke pihak ke tiga dan timbul beban bunga pinjaman.

Dampak lain yang timbul karena tingginya nilai dead stock adalah timbulnya biaya pameran yang relatif besar. Pameran 
yang diadakan oleh perusahaan memiliki tujuan utama yakni mengurangi dead stock yang ada dan menjual barang-barang tersebut dengan harga factory price.

Berdasarkan hasil analisa dan focus group discussion yang telah dilakukan penulis dengan pihak manajemen perusahaan dapat disimpulkan bahwa:

1. Ditemukan beban deadstock yang cukup material, yang mana penyebab utamanya ialah karena kurangnya informasi mengenai market wants

2. Pengaruh audit operasional terhadap pengendalian barang jadi di perusahaan sudah terlihat memberikan pengaruh yang positif. Terbukti setelah penerapan rekomendasi audit yang mulai dilakukan pada Januari 2018 terjadi penurunan beban deadstock

\section{Saran}

Berdasarkan hasil focus group discussion dengan manajemen, penulis menyampaikan beberapa saran sebagai berikut:

- Melakukan pendekatan kepada pemilik toko guna meningkatkan informasi mengenai customer wants

- Peningkatan ketrampilan salesmanship dengan memberikan pelatihan bagi para salesman

- Stock keeper lebih meningkatkan system pencatatan dan pengendalian jumlah orderhal ini untuk mencegah pemesanan yang sifatnya spekulatif.

- Menentukan jumlah persentase minimum dari target penjualan salesman untuk barang yang umurnya di atas 6 bulan

- Menjaga keseimbangan barang masuk dan barang keluar dengan cara selektif dalam menentukan desain produk yang akan diproduksi.
- Pengendalian batasan maksimum untuk persediaan barang jadi agar lebih diperketat

\section{Daftar Pustaka}

Adelina, R. (2012). Analisis Efektivitas dan Kontribusi Penerimaan Pajak Bumi dan Bangunan (PBB) terhadap Pendapatan Daerah Kabupaten Gresik. Unesa Journal.

Agoes, S. (2008). Auditing Pemeriksaan oleh Akuntan Publik. Jakarta: Lembaga Penerbit Fakultas Ekonomi Universitas Indonesia.

Agoes, S. (2012). Auditing Petunjuk Praktis Pemeriksaan Akuntan Oleh Akuntan Publik (4th ed.). Jakarta: Salemba Empat.

Arens, A. A., Elder, R. J., \& Beasley, M. S. (2014). Auditing and Assurance Services (15th ed.). Harlow: Pearson Education Limited.

Bayangkara, I. (2008). Audit Manajemen Prosedur dan Implementasi. Jakarta: Salemba Empat.

Bayangkara, I. (2015). Audit Manajemen Prosedur dan Implementasi (2nd ed.). Jakarta: Salemba Empat.

Blocher, E. J., Stout, D. E., \& Cokins, G. (2010). Cost Management (5th ed.). McGraw-Hill Irwin.

Cooper, D. R., \& S., P. (2008). Metode Riset Bisnis. Jakarta: erlangga.

Cooper, D. R., \& S., P. (2017). Metode Penelitian Bisnis (12th ed.). Jakarta: Salemba Empat.

Heizer, J., Render, B., \& Griffin, P. (2016). Operations Management (12th ed.). Toronto: Pearson.

Ikatan Akuntansi Indonesia. (2008). PSAK No 14: Persediaan. Jakarta: IAI.

Messier, W. F., Glover, S. M., \& Prawitt, D. F. (2014). Jasa Audit dan Assurance (8th ed.). Jakarta: Salemba Empat.

Moeller, R. R. (2016). Brink's Modern Internal Auditing (8th ed.). New 
Jersey.

Pickett, S. (2010). Internal Auditing Handbook (3rd ed.). WILEY.

Sambuaga, R. S. (2013). Evaluasi Akuntansi Persediaan pada PT Sukses Era Niaga Manado. EMBA.

Sangkala, E. (2013). Penerapan Akuntansi Persediaan untuk Perencanaan dan Pengendalian LPG pada PT. Emigas Sejahtera Minahasa. EMBA.

Sawyer, L. B. (2006). Audit Internal Sawyer (5th ed.). Jakarta: Salemba Empat.

Tunggal, A. W. (2008). Audit Manajemen. Jakarta: Rineka Cipta. 